\title{
Weapon-carrying is associated with more permissive gambling attitudes and perceptions and at-risk/problem gambling in adolescents
}

\author{
ZU WEI ZHAI ${ }^{1}$, RANI A. HOFF ${ }^{2}$, CAITLIN F. MAGRUDER ${ }^{1}$, MARVIN A. STEINBERG ${ }^{3}$, JEREMY WAMPLER $^{4}$ \\ SUCHITRA KRISHNAN-SARIN ${ }^{2}$ and MARC N. POTENZA ${ }^{2,5,6,7 *}$ \\ ${ }^{1}$ Department of Psychology, Middlebury College, Middlebury, VT, USA \\ ${ }^{2}$ Department of Psychiatry, Yale School of Medicine, New Haven, CT, USA \\ ${ }^{3}$ Retired, Guilford, CT, USA \\ ${ }^{4}$ Department of Mental Health and Addiction Services, Problem Gambling Services, Middletown, CT, USA \\ ${ }^{5}$ The Connecticut Council on Problem Gambling, Wethersfield, CT, USA \\ ${ }^{6}$ The Connecticut Mental Health Center, New Haven, CT, USA \\ ${ }^{7}$ Department of Neuroscience and Child Study Center, Yale School of Medicine, New Haven, CT, USA
}

(Received: January 29, 2019; revised manuscript received: June 25, 2019; accepted: July 24, 2019)

\begin{abstract}
Background and aims: A recent call to action highlighted the need to understand the relationship between problem gambling, violence, and health/functioning. As weapon-carrying and gambling behaviors are prevalent in adolescents, this study systematically examined relationships between weapon-carrying status and measures of problem gambling severity and gambling perceptions and attitudes, as well as how weapon-carrying status moderated relationships between problem gambling severity and measures of health/functioning and gambling behavior. Methods: Participants were 2,301 Connecticut high-school adolescents. $\chi^{2}$ and logistic regression models were conducted. Results: Weapon-carriers reported greater problem gambling severity, more permissive gambling perceptions, greater parental approval of gambling, and more family gambling concerns, compared to non-weapon-carriers. At-risk/problem gambling was more strongly associated with family, peers, and adult gambling partners among non-weapon-carriers (vs. weapon-carriers) and with machine gambling among weapon-carriers (vs. non-weapon-carriers). Discussion and conclusions: Greater problem gambling severity and more permissive gambling perceptions and perceived parental approval of gambling in weapon-carrying adolescents suggest that parent-child relationships are important to be considered in prevention efforts. The moderated relationship by weapon-carrying status between problem gambling severity and gambling partners suggests a problem gambling risk group that may be less linked to gambling with traditional social support groups, and this group may benefit from targeted interventions.
\end{abstract}

Keywords: weapon-carrying, gambling, violence, adolescent, high school, problem behaviors

\section{INTRODUCTION}

Weapon-carrying in adolescents, including possession of firearms, knives, or clubs, is a common type of youth violence that is a persistent concern in the United States and other countries. In a cross-national study, $10 \%-12 \%$ of boys and $2 \%-5 \%$ of girls reported having carried a weapon (Pickett et al., 2005). In the United States, $15.7 \%$ of adolescent students carried a weapon and $3.8 \%$ carried a weapon on school grounds in 2017 (Centers for Disease Control and Prevention, 2019). Weapon-carrying has been associated with heightened risk of mental and physical health problems, including depression, suicidal ideation, disordered eating, sexual victimization, and severe injuries requiring hospitalization (Muula, Rudatsikira, \& Siziya, 2008; Pickett et al., 2005; Ruggles \& Rajan, 2014). In addition, those who used weapons in fights were more likely to be regular smokers and sensation seekers, practice unsafe sex, and have poor family relationships (Thurnherr, Michaud, Berchtold, Akré, \& Suris, 2009).

Inasmuch as an estimated 60\%-70\% of North American youth have reported gambling and up to $10 \%$ of adolescents and young adults in the US have reported gambling problems in the past year (Barnes, Welte, Hoffman, \& Tidwell, 2009; Volberg, Gupta, Griffiths, Olason, \& Delfabbro, 2010), growing evidence point to a consistent relationship between weapon-carrying and problem gambling. Findings from the Centers for Disease Control and Prevention Youth Risk Behavioral Survey have shown that violence including carrying a weapon and physical fighting was associated with greater likelihoods of past-year gambling and gambling

* Corresponding author: Marc N. Potenza, MD, PhD; Connecticut Mental Health Center, 34 Park Street, New Haven, CT 06519, USA; Phone: +1 203974 7356; Fax: +1 203974 7366; E-mail: marc.potenza@yale.edu

This is an open-access article distributed under the terms of the Creative Commons Attribution-NonCommercial 4.0 International License, which permits unrestricted use, distribution, and reproduction in any medium for non-commercial purposes, provided the original author and source are credited, a link to the CC License is provided, and changes - if any - are indicated. 
problems, and remained significant even after controlling other risky behaviors of substance use and sexual activity (Proimos, DuRant, Pierce, \& Goodman, 1998). Furthermore, adolescents who carried a weapon were nearly three times more likely to have gambled in the past year (Goldstein, Walton, Cunningham, Resko, \& Duan, 2009). Similarly, individuals with problem gambling have greater odds of weapon-carrying, firearms carrying, as well as physical violence (Cook et al., 2015; Potenza et al., 2011; Slavin et al., 2013).

Both adolescent gambling and weapon-carrying are problem behaviors that share associations with negative health/functioning, including substance use, poor academic performance, depression, and delinquency (Cook et al., 2015; Mishra, Lalumière, Morgan, \& Williams, 2011; Yip et al., 2011). A problem behavior theory proposes that youth risky behaviors associated with weapons-carrying and gambling commonly co-occur from person-environment interactions and both may be contributing factors to a larger complex syndrome of "multiproblem" behaviors that portend serious health concerns (Donovan \& Jessor, 1985; Jessor \& Jessor, 1977; Kryszajtys et al., 2018; Pickett et al., 2002). Consistent with problem behavior theory, problem gambling and weapon-carrying were hypothesized to be linked through shared vulnerabilities, particularly in impulse control, family/peer relationships, and their interactions with youth environments (Mishra et al., 2011; Vitaro, Brendgen, Ladouceur, \& Tremblay, 2001).

Together, findings suggest that problem gambling and weapon-carrying impact subsequent health and function, and are strongly associated in adolescents. However, differences in complex health/functioning characteristics and gambling behavior correlates of problem gambling between adolescent students of different weapon-carrying status remain poorly understood. In addition, although both problem gambling and weapon-carrying are related to risk behaviors, few studies have directly examined interactions between problem gambling and weapon-carrying status on health/functioning (Kryszajtys et al., 2018). Understanding these relationships is critical to advancing prevention efforts focused on both gambling and weapon-carrying behaviors among youth.

Hence, this study examined the relationship between problem gambling severity and health/functioning, and gambling behaviors in adolescents stratified by weaponcarrying status. We hypothesized that weapon-carrying would be associated with more severe problem gambling; adolescents with weapon-carrying would have more permissive gambling perceptions and view problem gambling preventions as less important; and the relationship between problem gambling severity and health/functioning and gambling characteristics would differ between weaponcarrying and non-weapon-carrying adolescents.

Participants in this study have reported a variety of risky behaviors, and include adolescents who may carry a weapon for self-defense, to perpetrate violence, or both. Previous findings have shown that adolescent victimization and perpetration of violence and bullying are associated with weapon-carrying (Durant, Getts, Cadenhead, \& Woods, 1995; Erickson, Butters, Cousineau, Harrison, \& Korf, 2006; van Geel, Vedder, \& Tanilon, 2014). Both bullying victim and perpetrator status were shown to mediate obesity and weapon-carrying relationships, suggesting that significant health problems may occur in adolescents who attribute weapon-carrying to either violence perpetration or victimization (Kukaswadia, Craig, Janssen, \& Pickett, 2012). Adolescent perpetrators of violence are often also bullying victims and carry a weapon consequent to having experienced violence (Erickson et al., 2006; Leary, Kowalski, Smith, \& Phillips, 2003). Indeed, recent evidence showed that adolescents who perpetrated and were victims of bullying through electronic venues (i.e., cyberbullying) were 2.65 times more likely to prospectively report weaponcarrying 1 year later (Lu, Avellaneda, Torres, Rothman, \& Temple, 2019). As it is difficult to determine motivations for weapon-carrying, participants who endorsed weaponcarrying in this study were considered as a whole, as there was no indication for the rationale of weapon-carrying.

\section{METHODS}

\section{Recruitment and survey characteristics}

Recruitment, consenting procedures, and sample characteristics have been reported previously (Potenza et al., 2011; Schepis et al., 2008; Zhai et al., 2017). Briefly, invitations were extended through mailing 122 letters and follow-up calls to principals of 4-year and non-vocational or specialeducation high schools in Connecticut, USA. Seventy-eight schools did not respond and 13 declined. Additional targeted recruitment, conducted to ensure representation of all four geographical quadrants of Connecticut, and schools from the three tiers of the state's family-socioeconomicstatus-related district reference groups, yielded 10 schools that participated in the survey. Adolescents were surveyed over one academic year. For each school, the survey was administered on a single day by the research team. There was no monetary compensation and refusal rate was $<1 \%$.

Descriptions of the variables and classification of responses were previously presented (Potenza et al., 2011; Schepis et al., 2008; Yip et al., 2011). The survey contained 154 questions assessing demographic characteristics, health/functioning measures, gambling (defined as "any game you bet on for money or anything else of value"), and items derived from established measures (e.g., Massachusetts Gambling Screen by Shaffer, Labrie, Scanlan, \& Cummings, 1994). For this study, 2,301 adolescents completed the weapon-carrying measure and all 12 questions corresponding to inclusion criteria for problem/ pathological gambling.

\section{Measures}

Demographic characteristics. As reported previously (Schepis et al., 2008; Yip et al., 2011), sample demographics were consistent with findings reported in the 2000 Census of Connecticut residents aged 14-18 years. Demographic variables controlled for herein regarding adolescent problem gambling severity included gender, race/ethnicity, grade in school, and family structure (e.g., living with one parent). 
Problem gambling severity. Problem gambling severity was assessed using the Massachusetts Gambling Screen (Shaffer et al., 1994), a validated self-report assessment tool based on DSM-IV criteria for pathological gambling (American Psychiatric Association, 2000; Weinstock, Whelan, \& Meyers, 2004). The Massachusetts Gambling Screen (MAGS) was developed to yield an index for pathological gambling. Subscales had adequate reliability (Cronbach's $\alpha=.83-.87$ ). For predictive validity, the instrument was able to classify $96 \%$ of students as having pathological or non-pathological gambling (Shaffer et al., 1994).

Weapon-carrying. Weapon-carrying status was assessed using the question "During the past 30 days, on how many days did you carry a weapon, such as a gun, knife, or club?" This item is consistent with previous studies that similarly assessed weapon-carrying regardless of weapon type (Durant et al., 1995), or combined different weapon types into one factor (Kukaswadia et al., 2012).

Gambling perceptions. Adolescent perceptions of gambling and the importance of preventing problem gambling were assessed as described previously (Slavin et al., 2013; Yip et al., 2011). Participants indicated the importance (important/not important) on 15 items regarding gambling prevention approaches. Examples include "Checking identification for purchasing lottery tickets," "Hanging out with friends who do not gamble," and "Participating in activities that are fun and free of gambling." In addition, participants reported on perceived parental perceptions toward gambling (disapprove, approve, or neither) with the item "How do you think your parents would feel about you gambling, even once or twice, over the next 12 months?" Adolescents' perceptions of having family gambling problems (yes/no) were assessed with the question, "Has the gambling of a close family member caused you worry or concern?"

Health/functioning. As previously described (Slavin et al., 2013; Yip et al., 2011), health/functioning measures assessed the following domains: grade average, engagement in extracurricular activity (yes/no), lifetime regular tobacco smoking (never, occasionally, and regularly), lifetime marijuana use (yes/no), lifetime other drug use (yes/no), lifetime (yes/no) and past-30-days alcohol use [never, regular (1-5 days), light (6-9 days), moderate (10-19 days), and heavy (20-30 days)], and past-year sadness or hopelessness for $\geq 2$ consecutive weeks (yes/no). Height and weight were assessed to calculate body mass index (BMI). BMIs were categorized as underweight $(\leq 18.5)$, normal weight (18.6-24.9), overweight (25-29.9), and obese ( $\geq 30)$.

Gambling characteristics. Participants with past-year gambling responded on the presence (yes/no) of different gambling characteristics including: gambling location (online, school grounds, and casino), gambling triggers (pressure and anxiety), gambling reasons (excitement, financial, escape, and social), gambling partners (family, friends, other adults, strangers, and alone), time spent gambling per week ( $\leq 1$ and $\geq 2 \mathrm{hr}$ ), and gambling age of onset $(\leq 8,9-11,12-14$, and $\geq 15$ years old). Gambling types were classified into strategic gambling (i.e., so-called "games of skill" involving chance), non-strategic gambling (i.e., "games of chance" not involving skill), and machine gambling as previously defined (Yip et al., 2011). Machine gambling was determined by endorsement of having wagered on slot machines, poker machines, or other gambling machines.

\section{Procedure}

Problem gambling severity groups. Participants were stratified into three problem gambling severity groups based on MAGS responses. Adolescents with no past-year gambling were classified as non-gambling (NG). As in prior studies (Potenza et al., 2011; Slavin et al., 2013; Yip et al., 2011; Zhai et al., 2017) and US national epidemiological samples (Desai \& Potenza, 2008; Pilver, Libby, Hoff, \& Potenza, 2013a, 2013b), adolescents with past-year gambling but no diagnostic criteria were classified as low-risk gambling (LRG). Adolescents who endorsed one or more criteria were classified as at-risk/problem gambling (ARPG). Among the 2,301 adolescents, designations included $406(17.6 \%)$ with NG, 1,254 (54.5\%) with LRG, and $641(27.9 \%)$ with ARPG. For follow-up analyses, adolescents with gambling were also stratified based on the number of endorsed pathological-gambling criteria (Pilver et al., 2013b). Of the 1,895 adolescents who gambled, designations included 1,254 with 0 inclusionary criteria $(66.2 \%), 405$ with $1-2$ criteria $(21.4 \%), 115$ with $3-4$ criteria $(6.1 \%)$, and 121 with $\geq 5$ criteria $(6.4 \%)$.

Weapon-carrying groups. Adolescent were also stratified into two weapon-carrying groups. Those who gave a response of 0 days in which they carried weapons were designated as non-weapon-carrying, and responses greater than 0 were designated as weapon-carrying. Among the 2,301 adolescents in this study, $599(26 \%)$ reported weapon-carrying.

\section{Statistical analyses}

As described previously (Slavin et al., 2013; Yip et al., 2011), data were double-entered and random spot-checks of completed surveys were performed to ensure accuracy. Statistical analyses were conducted using SPSS 24 (Armonk, NY, USA). Pearson's $\chi^{2}$ analyses (two-tailed) compared demographic characteristics and gambling perceptions stratified by weapon-carrying status. A Bonferroni correction for multiple $\chi^{2}$ comparisons was applied such that $p$ values of $p \leq .0025$ were considered significant. Logistic regression models were constructed for binary outcomes and multinomial logistic regression models for categorical outcomes, stratified by weapon-carrying status, to calculate odds ratios (ORs) and $95 \%$ confidence intervals for the association between problem gambling severity and dependent variables. To determine the interaction between weapon-carrying status and problem gambling severity on dependent variables, main effects of weapon-carrying status and problem gambling severity, and the interaction term (weapon-carrying by problem gambling severity), were included in the models. All interaction models were adjusted for gender, grade level, race, and family structure and significance was set at $p \leq .05$.

\section{Ethics}

Among schools that were interested in participating, permission was obtained from school boards and/or 
superintendents as necessary. The institutional review board at Yale University and all data collection sites approved the passive parental consent and student assent procedures. Letters were sent to parents to provide information about the study and instructed them to contact the school should they deny the permission. Students were given the opportunity to decline participation. All procedures performed in human participants were in accordance with the ethical standards of the institutional and/or national research committee and with the 1964 Helsinki Declaration and its later amendments or comparable ethical standards.

\section{RESULTS}

\section{Demographic characteristics}

Demographic data are shown in Table 1. Among weaponcarriers, $78 \%$ were male and $21.7 \%$ were female, and $16.3 \%$ of weapon-carrying adolescents were aged $\leq 14$ years, $68.4 \%$ were between 15 and 17 years, and $15.3 \%$ were $\geq 18$ years. Among these students, 33.6\%, 24.5\%, $28.4 \%$, and $13.4 \%$ attended 9 th, 10 th, 11 th, and 12 th grades, respectively. Furthermore, $69 \%$ of weapon-carrying adolescents identified as Caucasian, $14.1 \%$ as African

Table 1. Sociodemographic characteristics stratified by weapon-carrying status

\begin{tabular}{|c|c|c|c|c|c|c|}
\hline \multirow[b]{2}{*}{ Variable } & \multicolumn{2}{|c|}{ Non-weapon-carrying $(N=1,702)$} & \multicolumn{2}{|c|}{ Weapon-carrying $(N=599)$} & \multirow[b]{2}{*}{$\chi^{2}$} & \multirow[b]{2}{*}{$p$} \\
\hline & $N$ & $\%$ & $N$ & $\%$ & & \\
\hline Gender & & & & & 162.06 & $<.0001$ \\
\hline Male & 810 & 48 & 459 & 78 & & \\
\hline Female & 877 & 52 & 127 & 21.7 & & \\
\hline \multicolumn{7}{|l|}{ Race/ethnicity } \\
\hline Caucasian & & & & & 3.97 & .046 \\
\hline No & 454 & 26.7 & 184 & 31 & & \\
\hline Yes & 1,245 & 73.3 & 410 & 69 & & \\
\hline African American & & & & & 7.64 & .006 \\
\hline No & 1,529 & 90 & 510 & 85.9 & & \\
\hline Yes & 170 & 10 & 84 & 14.1 & & \\
\hline Asian & & & & & 1.44 & .230 \\
\hline No & 1,620 & 95.4 & 559 & 94.1 & & \\
\hline Yes & 79 & 4.6 & 35 & 5.9 & & \\
\hline Hispanic & & & & & 14.49 & $<.0001$ \\
\hline No & 1,398 & 86.1 & 451 & 79.4 & & \\
\hline Yes & 225 & 13.9 & 117 & 20.6 & & \\
\hline Other & & & & & 5.39 & .020 \\
\hline No & 1,437 & 84.6 & 478 & 80.5 & & \\
\hline Yes & 262 & 15.4 & 116 & 19.5 & & \\
\hline Grade & & & & & 12.48 & .006 \\
\hline 9th & 482 & 28.4 & 200 & 33.6 & & \\
\hline 10th & 440 & 25.9 & 146 & 24.5 & & \\
\hline 11 th & 454 & 26.7 & 169 & 28.4 & & \\
\hline 12 th & 322 & 19 & 80 & 13.4 & & \\
\hline Age (years) & & & & & .03 & .990 \\
\hline$<14$ & 213 & 16.4 & 77 & 16.3 & & \\
\hline $15-17$ & 888 & 68.6 & 322 & 68.4 & & \\
\hline$>18$ & 194 & 15.0 & 72 & 15.3 & & \\
\hline Family structure & & & & & 33.44 & $<.0001$ \\
\hline One parent & 350 & 20.9 & 170 & 29 & & \\
\hline Two parents & 1,235 & 73.6 & 359 & 61.3 & & \\
\hline Other & 93 & 5.5 & 57 & 9.7 & & \\
\hline Problem gambling severity & & & & & 165.61 & $<.0001$ \\
\hline Non-gambling & 362 & 21.3 & 44 & 7.3 & & \\
\hline Low-risk gambling & 980 & 57.6 & 274 & 45.7 & & \\
\hline At-risk/problem gambling & 360 & 21.2 & 281 & 46.9 & & \\
\hline Pathological gambling criteria & & & & & 146.80 & $<.001$ \\
\hline None & 980 & 73.1 & 274 & 49.4 & & \\
\hline $1-2$ symptoms & 259 & 19.3 & 146 & 26.3 & & \\
\hline 3-4 symptoms & 63 & 4.7 & 52 & 9.4 & & \\
\hline$\geq 5$ symptoms & 38 & 2.8 & 83 & 15.0 & & \\
\hline
\end{tabular}

Note. Total sample size $(N=2,301)$. Percentages presented separately within weapon-carrying and non-weapon-carrying groups. 
American, 5.9\% as Asian American, 20.6\% as Hispanic, and $19.5 \%$ as "other race." Weapon-carrying status was associated with problem gambling severity. Weapon-carriers reported ARPG $(46.9 \%)$ more frequently relative to non-weapon-carriers (21.2\%). Among adolescents who gambled, weapon-carrying was associated with problem gambling severity levels $(p<.001)$. Weapon-carriers reported $1-2(26.3 \%), 3-4(9.4 \%)$, and $\geq 5(15.0 \%)$ criteria more frequently relative to non-weapon-carriers $(19.3 \%$, $4.7 \%$, and $2.8 \%$, respectively). Based on the sample characteristics, the study may not be sufficiently powered to reliably examine further interactions by multiple demographic variables (e.g., gender) between different weaponcarrying and problem gambling severity groups.

\section{Gambling perceptions}

$\chi^{2}$ results on gambling perceptions are shown in Table 2. A range of $55.8 \%-71.1 \%$ weapon-carrying adolescents rated gambling prevention and non-permissive measures as important, whereas a range of $66.5 \%-90.8 \%$ was found in non-weapon-carriers. Weapon-carriers, compared to nonweapon-carriers, were more likely to rate parental oversight and non-involvement in gambling as not important including: not having access to Internet gambling at home, parent/ guardian strictness about gambling, warnings from adults in family, learning about the risks of gambling from parents, having parents who do not gamble, adults not involving kids in gambling, and parent/guardian not permitting card games at home. Weapon-carriers were also more likely to rate environmental context and peer non-involvement in gambling as not important including: checking identification for purchasing lottery tickets; participating in activities that are fun and free of gambling; advertisements that show the problems associated with gambling; learning about the risk of gambling in school; hanging out with friends who do not gamble; warnings from, or listening to, peers; and learning about risks of gambling from peers. In addition, weaponcarriers reported greater parental approval of adolescent gambling and having concern for a close family member's gambling.

\section{Health/functioning measures}

Logistic and multinomial logistic regression analyses of health/functioning data are shown in Table 3. Among weapon-carrying adolescents, those with ARPG compared to NG were more likely to report smoking tobacco regularly $(p=.04)$ and heavy current alcohol use $(p=.02)$. Within non-weapon-carriers, those with LRG and ARPG compared to NG were more likely to report lifetime marijuana use (both $p<.001)$, smoking tobacco occasionally $(p=.001$; $p<.001)$ and regularly $(p=.01 ; p=.002)$, lifetime alcohol use (both $p<.001)$, and moderate $(p=.03 ; p=.04)$ and heavy alcohol use $(p=.03 ; p=.04)$. Non-weapon-carriers with ARPG compared to NG were more likely to report lifetime other drug use $(p=.004)$. The proportion of health/ functioning responses for each gambling group stratified by weapon-carrying status is shown in Table 4. Group differences were found for extracurricular activities and lifetime marijuana and other drug use for weapon-carriers and non-weapon-carriers, current smoking, and alcohol use in non-weapon-carriers, and dysphoria/depression in weapon-carriers.

Both weapon-carrying and non-weapon-carrying adolescents with LRG compared to NG were more likely to report having extracurricular activities $(p=.03 ; p=.02)$, while non-weapon-carrying adolescents with ARPG compared to $\mathrm{NG}$ were more likely to report extracurricular activities $(p=.001)$. Non-weapon-carriers with ARPG compared to NG were more likely to report a grade average of mostly C's $(p=.04)$ and dysphoria/depression $(p<.001)$. No significant interactions between weapon-carrying status and problem gambling severity were found. The proportions of substance use behaviors for each problem gambling criteria level stratified by weapon-carrying status are shown in Table 5. Among weapon-carriers and non-weapon-carriers, problem gambling severity levels were associated with greater frequencies of lifetime marijuana and other drug use (all $p \mathrm{~s}<.01$ ). In addition, symptom levels were associated with greater proportions of smoking tobacco regularly in weapon-carriers $(p<.001)$.

\section{Gambling characteristics}

The results of logistic and multinomial logistic regression analysis of gambling characteristics data are shown in Table 6. Among both weapon-carrying and nonweapon-carrying adolescents, ARPG compared to LRG group was more likely to report: non-strategic gambling $(p=.02 ; p=.03)$, machine gambling $(p<.001 ; p=.01)$, online gambling (all $p \mathrm{~s}<.001$ ), gambling on school grounds (both $p<.001$ ), casino gambling (both $p<.001$ ), pressure as a trigger for gambling (both $p<.001$ ), anxiety as a trigger for gambling (both $p<.001$ ), gambling for excitement (both $p<.001$ ), financial reasons (both $p<.001$ ), escape (both $p<.001)$ and social reasons $(p=.02$; $p<.001$ ), and gambling for $\geq 2$ hr per week (both $p<.001$ ).

Among non-weapon-carrying adolescents, the ARPG relative to the LRG group was more likely to report: strategic gambling $(p=.02)$ and gambling with family $(p=.002)$, friends $(p<.001)$, other adults $(p<.001)$, strangers $(p<.001)$, and alone $(p<.001)$. In weaponcarriers, the ARPG relative to the LRG group was more likely to report gambling with strangers $(p<.001)$ and alone $(p=.003)$. In addition, weapon-carriers with APRG compared to LRG were less likely to report gambling initiation at ages $\geq 15$ years old $(p=.05)$. Significant interactions between weapon-carrying status and problem gambling severity were found for: gambling with family $(p=.02)$, friends $(p<.001)$, and other adults $(p=.001)$ and machine gambling $(p=.003)$. After inverse-transforming ORs less than 1 (1/OR), weapon-carriers with ARPG versus those with $\mathrm{LRG}$ were $1.75[1 /(\mathrm{OR}=0.57)]$ times less likely to gamble with family, and $2.7[1 /(\mathrm{OR}=0.37)]$ times less likely to gamble with friends or other adults, relative to non-weapon-carriers.

Whereas a greater likelihood of weapon-carrying has been observed in boys (Pickett et al., 2005), gambling behaviors in male adolescents showed similar interactions between problem gambling severity and weapon-carrying (Supplementary Table S1). Weapon-carrying with ARPG 
Table 2. Gambling-related perceptions and attitudes in weapon-carrying and non-weapon-carrying adolescents

\begin{tabular}{|c|c|c|c|c|c|c|}
\hline \multirow[b]{2}{*}{ Variable } & \multicolumn{2}{|c|}{ Non-weapon-carrying } & \multicolumn{2}{|c|}{ Weapon-carrying } & \multirow[b]{2}{*}{$\chi^{2}$} & \multirow[b]{2}{*}{$p$} \\
\hline & $N$ & $\%$ & $N$ & $\%$ & & \\
\hline Perceived parental perception of gambling & & & & & 50.4 & $<.0001$ \\
\hline Disapprove & 636 & 44.4 & 175 & 34.9 & & \\
\hline Neither approve nor disapprove & 694 & 48.4 & 237 & 47.2 & & \\
\hline Approve & 104 & 7.3 & 90 & 17.9 & & \\
\hline \multicolumn{7}{|l|}{ Importance for preventing gambling problems in teens } \\
\hline Checking identification for purchasing lottery tickets & & & & & 59.98 & $<.0001$ \\
\hline Not important & 248 & 15.4 & 169 & 30.5 & & \\
\hline Important & 1,361 & 84.6 & 386 & 69.5 & & \\
\hline Hanging out with friends who do not gamble & & & & & 44.21 & $<.0001$ \\
\hline Not important & 382 & 23.9 & 213 & 38.7 & & \\
\hline Important & 1,213 & 76.1 & 338 & 61.3 & & \\
\hline Participating in activities that are fun and free of gambling & & & & & 80.4 & $<.0001$ \\
\hline Not important & 238 & 14.9 & 178 & 32.5 & & \\
\hline Important & 1,357 & 84.8 & 370 & 67.5 & & \\
\hline \multicolumn{7}{|l|}{ Fear of losing valuable possessions, close friends, and relatives } \\
\hline Not important & 147 & 9.2 & 126 & 22.9 & 68.35 & $<.0001$ \\
\hline Important & 1,444 & 90.8 & 425 & 77.1 & & \\
\hline \multicolumn{7}{|l|}{ Advertisements that show the problems associated with gambling } \\
\hline Not important & 327 & 20.7 & 201 & 36.7 & 55.59 & $<.0001$ \\
\hline Important & 1,252 & 79.3 & 347 & 63.3 & & \\
\hline Not having access to Internet gambling at home & & & & & 33.35 & $<.0001$ \\
\hline Not important & 522 & 32.9 & 255 & 46.7 & & \\
\hline Important & 1,064 & 67.1 & 291 & 53.3 & & \\
\hline Parent/guardian strictness about gambling & & & & & 47.53 & $<.0001$ \\
\hline Not important & 282 & 17.8 & 174 & 31.8 & & \\
\hline Important & 1,303 & 82.2 & 373 & 68.2 & & \\
\hline Warning from adults in family & & & & & 52.39 & $<.0001$ \\
\hline Not important & 281 & 17.8 & 177 & 32.5 & & \\
\hline Important & 1,302 & 82.2 & 367 & 67.5 & & \\
\hline Warning from, or listening to, peers & & & & & 68.07 & $<.0001$ \\
\hline Not important & 256 & 16.2 & 179 & 32.8 & & \\
\hline Important & 1,320 & 83.9 & 367 & 67.2 & & \\
\hline Having parents who do not gamble & & & & & 65.19 & $<.0001$ \\
\hline Not important & 291 & 18.4 & 192 & 35.2 & & \\
\hline Important & 1,292 & 81.6 & 354 & 64.8 & & \\
\hline Learning about the risks of gambling in school & & & & & 53.62 & $<.0001$ \\
\hline Not important & 339 & 21.5 & 204 & 37.3 & & \\
\hline Important & 1,241 & 78.5 & 343 & 62.7 & & \\
\hline Learning about the risks of gambling from parents & & & & & 63.53 & $<.0001$ \\
\hline Not important & 258 & 16.3 & 176 & 32.2 & & \\
\hline Important & 1,325 & 83.7 & 370 & 67.8 & & \\
\hline Learning about the risks of gambling from peers & & & & & 48.73 & $<.0001$ \\
\hline Not important & 314 & 19.9 & 190 & 34.5 & & \\
\hline Important & 1,267 & 80.1 & 360 & 65.5 & & \\
\hline Adults not involving kids in gambling & & & & & 83.88 & $<.0001$ \\
\hline Not important & 235 & 14.9 & 180 & 32.9 & & \\
\hline Important & 1,343 & 85.1 & 367 & 67.1 & & \\
\hline Parent/guardian not permitting card games (for money) at home & & & & & 20.09 & $<.0001$ \\
\hline Not important & 529 & 33.5 & 242 & 44.2 & & \\
\hline Important & 1,051 & 66.5 & 306 & 55.8 & & \\
\hline Family concern & & & & & 9.44 & 0.0021 \\
\hline No & 1,387 & 88.4 & 453 & 83.3 & & \\
\hline Yes & 182 & 11.6 & 91 & 16.7 & & \\
\hline
\end{tabular}

as compared to weapon-carrying with LRG was 2.15 times more likely to be associated with machine gambling, and $1.72[1 /(\mathrm{OR}=0.58)], 3.8[1 /(\mathrm{OR}=0.26)]$, and
$2.8[1 /(\mathrm{OR}=0.36)]$ times less likely to be associated with gambling with family, friends, or other adults, respectively. 
Zhai et al.

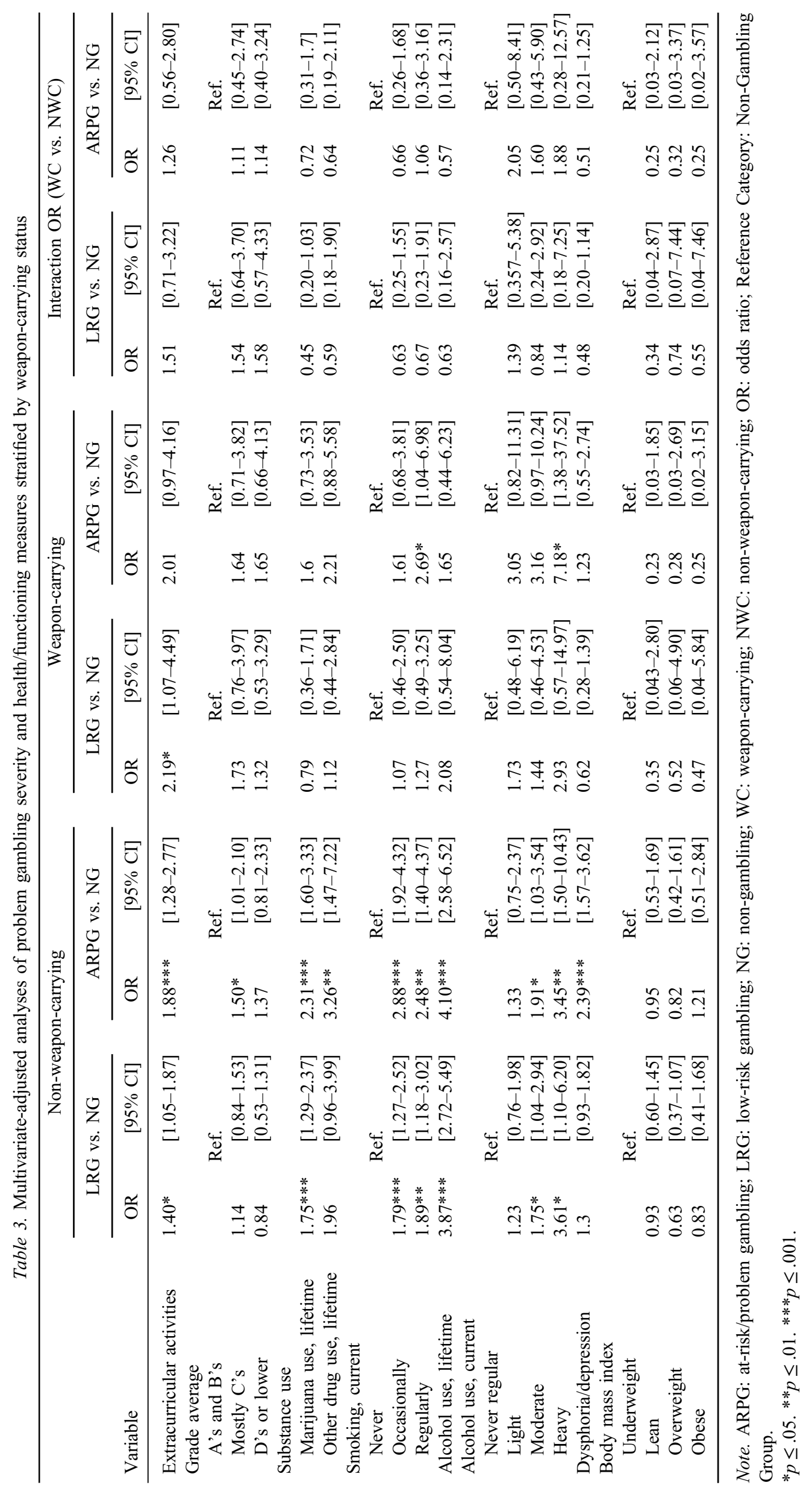


Adolescent weapon-carrying and gambling

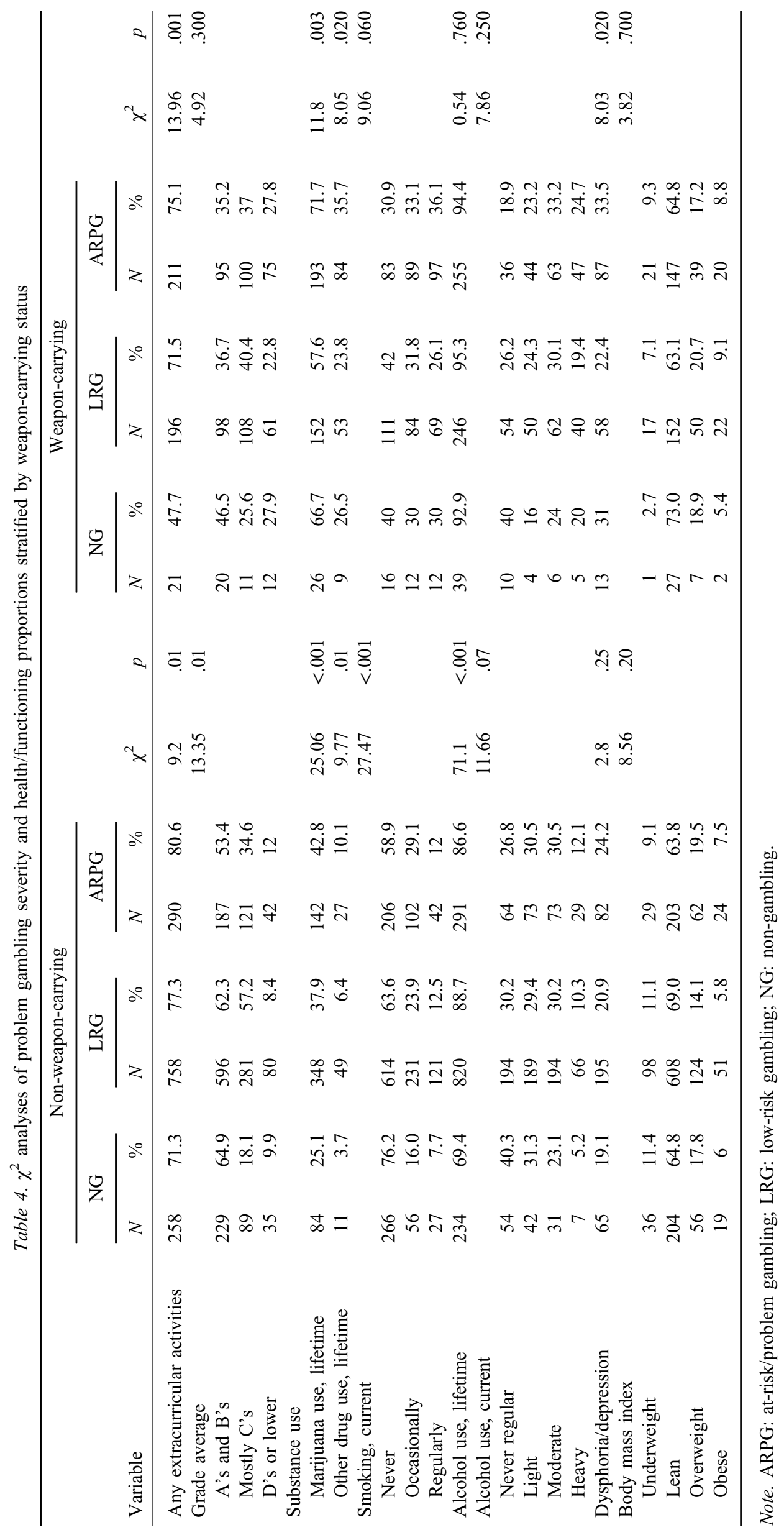




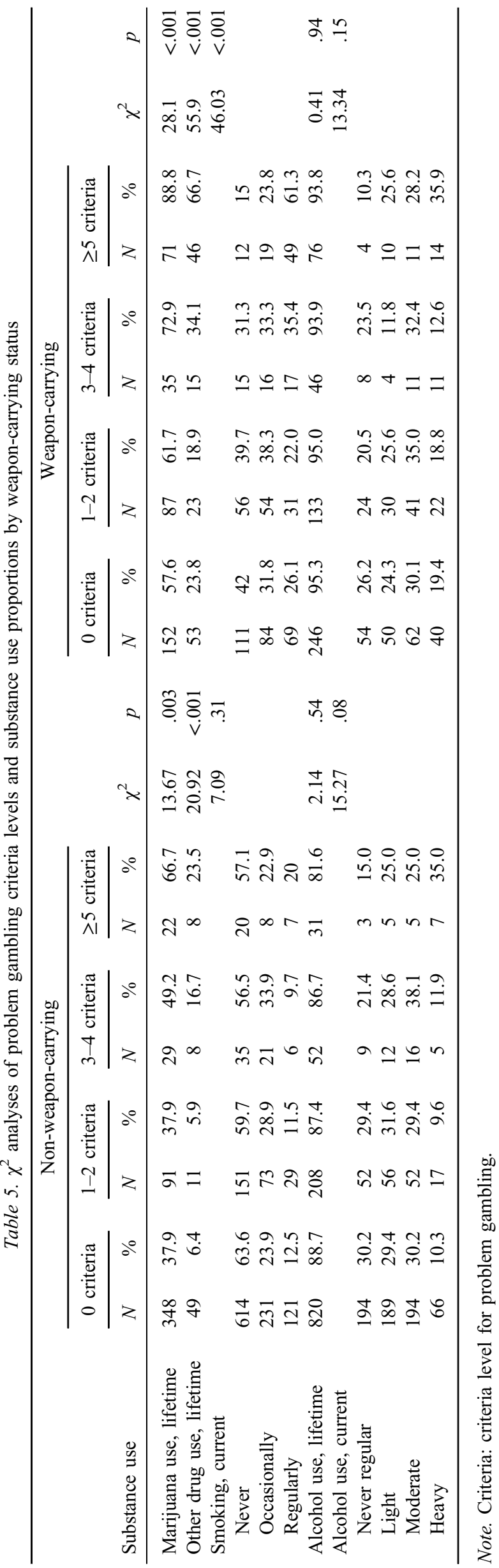

\section{DISCUSSION AND CONCLUSIONS}

A recent call to action highlighted the critical importance for understanding the relationship between problem gambling and violence and advocated for greater support for research in prevention of health and behavioral risks associated with gambling (Weinstock, 2018). This is one of the first studies, to our knowledge, that investigated self-reported gambling perceptions, gambling characteristics and health/functioning correlates, of problem gambling severity among adolescents who endorsed or denied carrying a weapon, as well as the interaction effects between weapon-carrying and problem gambling severity in behavioral correlates. In line with the first hypothesis, weapon-carrying status was associated with problem gambling severity, with a larger proportion endorsing ARPG among weapon-carrying adolescents, relative to non-weapon-carrying adolescents. Supporting the second hypothesis, weapon-carriers had more permissive perceptions of gambling, and a larger proportion rated prevention methods as not important, relative to nonweapon-carriers. The third hypothesis was partially supported as the associations between problem gambling severity and several gambling characteristics, but not health/functioning measures, were different among weaponcarriers and non-weapon-carriers.

The association between problem gambling severity and weapon-carrying is consistent with previous studies of adolescents (Cook et al., 2015; Goldstein et al., 2009; Potenza et al., 2011; Slavin et al., 2013). Weapon-carrying in youth has been suggested to indicate "violent lifestyles" that include substance use, violence, and antisocial behavior as described by the problem behavior theory (Jessor \& Jessor, 1977; Pickett et al., 2005). Whether weapon-carrying directly supports the development of gambling habits or whether problem gambling promotes violence including weapon-carrying to manage the consequences of gambling behaviors (or other possibilities) is unclear. Previous research on the relationship between problem gambling and criminal activity suggested that individuals with gambling problems may engage in illegal acts to support gambling (Adolphe, Khatib, van Golde, Gainsbury, \& Blaszczynski, 2019; Mishra et al., 2011; Turner, Preston, Saunders, McAvoy, \& Jain, 2009). As criminal activities often involve delinquent and antisocial behaviors (Magoon, Gupta, \& Derevensky, 2005), it is possible that adolescents initiate weapon-carrying consequent to existing problem gambling to maintain gambling behaviors. However, further research is necessary to elucidate the pathway between weapon-carrying and problem gambling and possible gambling-related motivations for weapon-carrying.

ARPG and weapon-carrying may also be associated through overlapping determinants of problem behaviors. Problem gambling has previously been shown to co-occur with antisocial personality disorder and conduct disorder, and their association was predominately explained by common genetic factors (Slutske et al., 2001). Both problem gambling and antisocial behavior have been individually associated with impulsivity (Leeman \& Potenza, 2012; Moffitt, Caspi, Harrington, \& Milne, 2002), and significant proportions of variance in gambling, problem gambling, and 
Table 6. Multivariate-adjusted analyses of problem gambling severity and gambling characteristics stratified by weapon-carrying status

\begin{tabular}{|c|c|c|c|c|c|c|}
\hline \multirow[b]{3}{*}{ Variable } & \multirow{2}{*}{\multicolumn{2}{|c|}{$\begin{array}{c}\text { Non-weapon-carrying } \\
\text { ARPG vs. LRG }\end{array}$}} & \multirow{2}{*}{\multicolumn{2}{|c|}{$\begin{array}{l}\text { Weapon-carrying } \\
\text { ARPG vs. LRG }\end{array}$}} & \multirow{2}{*}{\multicolumn{2}{|c|}{$\frac{\text { Interaction OR [WC vs. NWC] }}{\text { ARPG vs. LRG }}$}} \\
\hline & & & & & & \\
\hline & OR & {$[95 \% \mathrm{CI}]$} & OR & {$[95 \% \mathrm{CI}]$} & Interaction OR & {$[95 \% \mathrm{CI}]$} \\
\hline \multicolumn{7}{|l|}{ Gambling types } \\
\hline Strategic & $2.13^{*}$ & {$[1.13-4.01]$} & 1.00 & {$[0.46-2.20]$} & 0.51 & [0.19-1.34] \\
\hline Non-strategic & $1.37^{*}$ & [1.03-1.81] & $1.66^{*}$ & {$[1.10-2.48]$} & 1.20 & {$[0.75-1.93]$} \\
\hline Machine & $1.56^{* *}$ & [1.15-2.13] & $3.56^{* * *}$ & {$[2.25-5.41]$} & $2.17 * *$ & {$[1.31-3.60]$} \\
\hline \multicolumn{7}{|l|}{ Gambling locations } \\
\hline Online & $2.68 * * *$ & {$[1.92-3.74]$} & $3.64 * * *$ & {$[1.75-4.00]$} & 0.92 & {$[0.55-1.55]$} \\
\hline School & $4.66 * * *$ & {$[3.46-6.28]$} & $3.19 * * *$ & {$[2.14-4.74]$} & 0.74 & {$[0.45-1.21]$} \\
\hline Casino & $3.86^{* * *}$ & {$[1.74-4.68]$} & $5.15^{* * *}$ & {$[2.86-9.29]$} & 1.70 & {$[0.81-3.57]$} \\
\hline \multicolumn{7}{|l|}{ Triggers for gambling } \\
\hline Pressure & $2.97 * * *$ & {$[1.87-4.71]$} & $8.70 * * *$ & [3.95-19.16] & 2.38 & {$[0.97-5.80]$} \\
\hline Anxiety & $20.27 * * *$ & {$[6.80-60.42]$} & $10.22 * * *$ & [4.19-24.95] & 0.45 & {$[0.11-1.78]$} \\
\hline \multicolumn{7}{|l|}{ Reasons for gambling } \\
\hline Excitement & $3.40 * * *$ & {$[2.57-4.49]$} & $3.18 * * *$ & {$[2.18-4.63]$} & 0.98 & {$[0.62-1.55]$} \\
\hline Financial reasons & $3.39 * * *$ & {$[2.54-4.42]$} & $2.78 * * *$ & {$[1.87-4.12]$} & 0.84 & {$[0.52-1.36]$} \\
\hline Escape & $11.80 * * *$ & [4.87-28.59] & $6.03 * * *$ & {$[2.70-13.46]$} & 0.47 & {$[0.15-1.50]$} \\
\hline Social reasons & $1.86^{* * *}$ & {$[1.41-2.45]$} & $1.55^{*}$ & {$[1.07-2.24$} & 0.82 & {$[0.52-1.29]$} \\
\hline \multicolumn{7}{|l|}{ Gambling partners } \\
\hline Family & $1.55 * *$ & [1.18-2.03] & 0.86 & {$[0.59-1.25]$} & $0.57^{*}$ & {$[0.36-0.90]$} \\
\hline Friends & $2.41 * * *$ & {$[1.71-3.40]$} & 0.94 & {$[0.61-1.45]$} & $0.37 * * *$ & {$[0.22-0.64]$} \\
\hline Other adults & $3.64 * * *$ & {$[2.47-5.37]$} & 1.41 & {$[0.90-2.22]$} & $0.37 * * *$ & {$[0.21-0.67]$} \\
\hline Strangers & $5.92 * * *$ & [3.29-10.66] & $3.51 * * *$ & {$[1.99-6.21]$} & 0.63 & [0.28-1.39] \\
\hline Alone & $4.52 * * *$ & {$[2.77-7.38]$} & $2.57 * *$ & {$[1.37-4.81]$} & 0.66 & {$[0.31-1.43]$} \\
\hline \multicolumn{7}{|c|}{ Weekly time spent gambling } \\
\hline $1 \mathrm{hr}$ or less & \multicolumn{2}{|c|}{ Ref. } & \multicolumn{2}{|c|}{ Ref. } & \multicolumn{2}{|c|}{ Ref. } \\
\hline$\geq 2 \mathrm{hr}$ & $6.06^{* * *}$ & {$[3.93-9.37]$} & $3.39 * * *$ & {$[2.12-5.42]$} & 0.55 & {$[0.29-1.03]$} \\
\hline \multicolumn{7}{|c|}{ Age of onset of gambling } \\
\hline$\leq 8$ years old & \multicolumn{2}{|c|}{ Ref. } & \multicolumn{2}{|c|}{ Ref. } & \multicolumn{2}{|c|}{ Ref. } \\
\hline $9-11$ years old & 1.08 & {$[0.62-1.86]$} & 0.99 & {$[0.54-1.81]$} & 0.87 & [0.39-1.93] \\
\hline $12-14$ years old & 0.67 & [0.41-1.09] & 0.95 & {$[0.57-1.61]$} & 1.36 & [0.68-2.73] \\
\hline$\geq 15$ years old & 0.63 & [0.38-1.03] & $0.53^{*}$ & [0.28-0.99] & 0.83 & [0.39-1.80] \\
\hline
\end{tabular}

Note. ARPG: at-risk/problem gambling; LRG: low-risk gambling; WC: weapon-carrying; NWC: non-weapon-carrying; OR: odds ratio; CI: confidence interval; Reference category: low-risk gambling.

${ }^{*} p \leq .05 . * * p \leq .01 . * * * p \leq .001$.

antisocial behavior have been explained by risk-accepting tendencies including impulsivity, sensation seeking, and poor self-control (Mishra et al., 2011). Inasmuch as behavioral regulation develops throughout adolescence, findings from the National Longitudinal Study of Adolescent Health indicated that weapon-carrying likelihood was highest during age 15-17 years, and declined by age 18-21 years (Kodjo, Auinger, \& Ryan, 2003). This is consistent with this study findings of lower weapon-carrying likelihoods in Grade 12 students. Similarly, previous reports on our sample demonstrated that early-onset gambling (prior to 12 years old) was associated with a higher likelihood of ARPG (43\%) relative to later-onset gambling (32\%; Rahman et al., 2012).

Weapon-carrying adolescents reported more permissive attitudes toward gambling across multiple measures. Of note, a lower proportion of weapon-carrying adolescents rated methods that involved parents not engaging in and not exposing children to gambling as not important in preventing gambling problems. Adolescents who perceive family members as participating in, and being more permissive of, gambling may themselves regard gambling as more acceptable and less harmful, which may increase the risk of problem gambling (Campbell, Derevensky, Meerkamper, \& Cutajar, 2011; Zhai et al., 2017). We found that weaponcarrying adolescents were less likely to report having parents who disapproved of gambling and more likely to report having a family member with concerning levels of gambling. It is possible that perceptions of permissive attitudes toward gambling and modeling of gambling behaviors by parents may foster permissive attitudes toward similar gambling behaviors that co-occur with weaponcarrying in adolescents.

Parental permissive attitudes toward, and engagement in, gambling may be indicative of broader problems in parenting behavior. We found that a greater proportion of weaponcarriers rated parental monitoring and involvement items, 
including parent/guardian strictness about gambling and learning about the risk of gambling from parents, as not important. In addition to parental modeling of gambling behaviors, poorer monitoring of, lower trust of and poorer communication with adolescent children was previously associated with problem gambling severity (Magoon \& Ingersoll, 2006). Weapon-carrying youth previously reported poorer parent-child relationships and permissive parenting including low parental monitoring and support (Calhoun, Glaser, Peiper, \& Carr, 2015). More permissive and non-supportive parenting may foster development of permissive attitudes toward gambling among weaponcarrying adolescents, and amplify the risk of problem gambling. The relationship between weapon-carrying, parenting behavior, and gambling attitudes may be considered in the development of prevention programs for problem gambling. Inclusion of metrics for weapon-carrying, as well as permissive parenting behavior including low monitoring and involvement, may help identify youth at especially high risk of problem gambling. Emphasizing the importance of building strong parent-child relationships may be next steps for preventing co-occurring problem behaviors and risk of problem gambling.

The association between ARPG and gambling characteristics was similar between weapon-carrying and non-weaponcarrying adolescents with the exception of relationships with machine gambling and gambling with family, friends, and other adults. The association between ARPG and gambling with family, friends, and other adults was stronger in non-weapon-carriers compared to weapon-carriers. In contrast to non-weapon-carriers, the lack of associations between ARPG and gambling with familial and adult social partners in weapon-carriers suggests their problem gambling may be less influenced by social gambling, and rather contingent on asocial or solitary gambling. Indeed, gambling with strangers and alone were the only gamblingpartner variables associated with ARPG in weapon-carrying adolescents. Although not statistically different from non-weapon carriers, the odds of gambling for social reasons were numerically lower among weapon-carriers with ARPG. Furthermore, the association between ARPG and machine gambling was significantly greater in weaponcarriers, compared to non-weapon-carriers. Engagement in machine gambling (e.g., playing slot machines, poker machines, or other gambling machines) as well as online gambling has been suggested to shift individuals from social to asocial forms of gambling and increase interindividual isolation (Griffiths, 1995, 1999). As gambling in severe problem gamblers was previously described as a "solitary activity," it has been hypothesized that machine gambling and emerging electronic gambling technologies, through its asocial context, may increase gambling problems (Griffiths, 1995). The extent to which such solitary tendencies in conjunction with weapon-carrying and gambling problems may lay the foundation for current or future violent acts (e.g., intimate partner violence and shootings that have been linked to gambling, isolation, and access to weapons) requires further research (Roberts et al., 2018; Weinstock, 2018). Although it is important to note that different jurisdictions may have different regulations regarding gambling, there are often similarities in relationships between risk behaviors. Similar to alcohol use, gambling may occur at young ages. Within the US, $20 \%-86 \%$ middle- and highschool students previously gambled, especially on gambling machines (Jacobs, 2005). Reviews of international studies highlighted machine gambling as among the most prevalent gambling types in several countries, and this form was associated with more gambling-related problems (Calado, Alexandre, \& Griffiths, 2017).

On the whole, the results suggest that weapon-carrying adolescents may represent a high-risk subgroup for ARPG characterized by asocial behavior. Important next steps for problem gambling and violence prevention may focus on the importance of building supportive relationships with family and peer groups and education on risky social contexts. Future problem gambling assessments may also include weapons involvement to explore the underlying core features shared by gambling and violence. These findings may inform preventions including mindfulness-based therapies that may reduce the risk of gambling problems and violence (de Lisle, Dowling, \& Sabura Allen, 2011; Kelley \& Lambert, 2012).

The study has multiple strengths and limitations. Given the numbers of adolescent participants in each problemgambling-severity-by-weapon-carrying group, power to detect certain interactions between a large numbers of factors at once is limited. The weapon-carrying measure did not differentiate between types of weapons or weapon-carrying locations (e.g., school and public), and did not account for whether weapon-carrying was related to bullying victimization or perpetration. Participants may be unwilling to report sensitive information on victimization and perpetration related to weapon-carrying. Recent evidence indicated that cyberbullying perpetration, but not victimization, was related to weapon-carrying 1 year later, while weapon-carrying prospectively predicted cyberbullying victimization, but not perpetration ( $\mathrm{Lu}$ et al., 2019). Data from other reporters including parents were not available to verify self-reports. However, adolescents may not disclose sensitive information, including weapon-carrying, and report from others may not be particularly accurate. It is thus important for future research to examine weapon-carrying motivations and contexts as related to adolescent problem gambling severity. While the sample was collected from schools across Connecticut, generalizability to national or international contexts is limited. The data were collected in 2006, during a different gambling environment. The findings, however, may provide an important historical context for additional studies examining more current assessments of gambling behavior and perceptions, weapon-carrying, and health/functioning, which also are needed. Furthermore, the cross-sectional data limit elucidation of directional pathways between weapon-carrying, problem gambling severity, and their correlates. Longitudinal data will be needed to further explicate the mechanisms underlying the co-occurrence of weapon-carrying and problem gambling.

This is one of the first studies to demonstrate that weapon-carrying adolescents exhibited more permissive attitudes toward gambling, and had stronger associations between ARPG and machine gambling and weaker associations between ARPG and familial and peer gambling partners, compared to non-weapon-carrying adolescents. 
These findings reinforce the need to better understand the impact of social contexts and family-child relationships in the etiology of problem gambling and weapon-related violence. Prevention efforts in schools and communities that bolster secure relationships between adolescents and parents, and normative peers, and protect against solitary/asocial behaviors may be important for ameliorating risks of problem gambling and weapon-carrying.

Funding sources: This project was supported by National Institute of Health (grant numbers R01 DA019039 and RL1 AA017539). This work was also supported by the Connecticut Mental Health Center, the Connecticut State Department of Mental Health and Addiction Services, the Connecticut Council on Problem Gambling, and a Center of Excellence in Gambling Research Award from the National Center for Responsible Gaming. The funding agencies had no role in data collection or analysis or in the decision to submit the paper for publication.

Authors' contribution: Drs. RAH, SK-S, and MNP designed the survey with Dr. MAS advising on the inclusion of gambling-related questions. Dr. ZWZ and Ms. CFM conducted analyses and worked with Dr. MNP to develop initial drafts of the manuscript. All authors provided critical feedback with respect to the content of the manuscript. They also had full access to all data in the study and take responsibility for the integrity of the data and the accuracy of the data analysis.

Conflict of interest: The authors report no conflicts of interest with respect to the content of this manuscript. Dr. MNP has consulted for and advised Shire, INSYS Rivermend Health, Opiant/Lakelight Therapeutics, and Jazz Pharmaceuticals; received research support from the National Institutes of Health, Mohegan Sun Casino, and the National Center for Responsible Gaming; participated in surveys, mailings, or telephone consultations related to drug addiction, impulse-control disorders, or other health topics; consulted for law offices and the federal public defender's office in issues related to impulse-control and addictive disorders; provided clinical care in the Connecticut Department of Mental Health and Addiction Services Problem Gambling Services Program; performed grant reviews for the National Institutes of Health and other agencies; edited journals and journal sections; given academic lectures in grand rounds, CME events, and other clinical/scientific venues; and generated books or chapters for publishers of mental health texts. Other authors report no disclosures. The views presented in this manuscript represent those of the authors and not necessarily those of the funding agencies.

\section{REFERENCES}

Adolphe, A., Khatib, L., van Golde, C., Gainsbury, S. M., \& Blaszczynski, A. (2019). Crime and gambling disorders: A systematic review. Journal of Gambling Studies, 35(2), 395-414. doi:10.1007/s10899-018-9794-7
American Psychiatric Association. (2000). Diagnostic and statistical manual of mental disorders (4th ed.). Washington, DC: American Psychiatric Association.

Barnes, G. M., Welte, J. W., Hoffman, J. H., \& Tidwell, M. C. (2009). Gambling, alcohol, and other substance use among youth in the United States. Journal of Studies on Alcohol and Drugs, 70(1), 134-142. doi:10.15288/jsad.2009.70.134

Calado, F., Alexandre, J., \& Griffiths, M. D. (2017). Prevalence of adolescent problem gambling: A systematic review of recent research. Journal of Gambling Studies, 33(2), 397-424. doi:10.1007/s10899-016-9627-5

Calhoun, G. B., Glaser, B. A., Peiper, J., \& Carr, B. M. (2015). Parental monitoring and perceptions related to Juvenile offenders who fight and carry weapons. Journal of Family Violence, 30(5), 643-650. doi:10.1007/s10896-015-9682-1

Campbell, C., Derevensky, J., Meerkamper, E., \& Cutajar, J. (2011). Parents' perceptions of adolescent gambling: A Canadian national study. Journal of Gambling Issues, 25(25), 36-53. doi:10.4309/jgi.2011.25.4

Centers for Disease Control and Prevention. (2019). 1991-2017 high school youth risk behaviors survey data. Retrieved November 11, 2019, from http://nccd.cdc.gov/youthonline/

Cook, S., Turner, N. E., Ballon, B., Paglia-Boak, A., Murray, R., Adlaf, E. M., Ilie, G., den Dunnen, W., \& Mann, R. E. (2015). Problem gambling among Ontario students: Associations with substance abuse, mental health problems, suicide attempts, and delinquent behaviours. Journal of Gambling Studies, 31(4), 1121-1134. doi:10.1007/s10899-014-9483-0

de Lisle, S. M., Dowling, N. A., \& Sabura Allen, J. (2011). Mindfulness-based cognitive therapy for problem gambling. Clinical Case Studies, 10(3), 210-228. doi:10.1177/1534650 111401016

Desai, R. A., \& Potenza, M. N. (2008). Gender differences in the associations between past-year gambling problems and psychiatric disorders. Social Psychiatry and Psychiatric Epidemiology, 43(3), 173-183. doi:10.1007/s00127-0070283-z

Donovan, J. E., \& Jessor, R. (1985). Structure of problem behavior in adolescence and young adulthood. Journal of Consulting and Clinical Psychology, 53(6), 890-904. doi:10.1037/0022006X.53.6.890

Durant, R. H., Getts, A. G., Cadenhead, C., \& Woods, E. R. (1995). The association between weapon carrying and the use of violence among adolescents living in and around public housing. Journal of Adolescent Health, 17(6), 376-380. doi:10.1016/1054-139X(95)00030-V

Erickson, P. G., Butters, J. E., Cousineau, M. M., Harrison, L., \& Korf, D. (2006). Girls and weapons: An international study of the perpetration of violence. Journal of Urban Health, 83(5), 788-801. doi:10.1007/s11524-006-9038-5

Goldstein, A. L., Walton, M. A., Cunningham, R. M., Resko, S. M., \& Duan, L. (2009). Correlates of gambling among youth in an inner-city emergency department. Psychology of Addictive Behaviors, 23(1), 113-121. doi:10.1037/a0013912

Griffiths, M. (1995). Adolescent gambling. London, UK: Routledge.

Griffiths, M. (1999). Gambling technologies: Prospects for problem gambling. Journal of Gambling Studies, 15(3), 265-283. doi:10.1023/A:1023053630588

Jacobs, D. F. (2005). Youth gambling in North America. In J. L. Derevensky \& R. Gupta (Eds.), Gambling problems in youth: 
Theoretical and applied perspectives (pp. 1-24). Boston, MA: Springer US.

Jessor, R., \& Jessor, S. L. (1977). Problem behavior and psychosocial development: A longitudinal study of youth. New York: Academic Press.

Kelley, T. M., \& Lambert, E. G. (2012). Mindfulness as a potential means of attenuating anger and aggression for prospective criminal justice professionals. Mindfulness, 3(4), 261-274. doi:10.1007/s12671-012-0090-9

Kodjo, C. M., Auinger, P., \& Ryan, S. A. (2003). Demographic, intrinsic, and extrinsic factors associated with weapon carrying at school. JAMA Pediatrics, 157(1), 96-103. doi:10.1001/ archpedi.157.1.96

Kryszajtys, D. T., Hahmann, T. E., Schuler, A., Hamilton-Wright, S., Ziegler, C. P., \& Matheson, F. I. (2018). Problem gambling and delinquent behaviours among adolescents: A scoping review. Journal of Gambling Studies, 34(3), 893-914. doi:10.1007/s10899-018-9754-2

Kukaswadia, A., Craig, W., Janssen, I., \& Pickett, W. (2012). Bullying as a mediator of relationships between adiposity status and weapon carrying. International Journal of Public Health, 57(3), 505-512. doi:10.1007/s00038-011-0329-6

Leary, M. R., Kowalski, R. M., Smith, L., \& Phillips, S. (2003). Teasing, rejection, and violence: Case studies of the school shootings. Aggressive Behavior, 29(3), 202-214. doi:10.1002/ ab. 10061

Leeman, R. F., \& Potenza, M. N. (2012). Similarities and differences between pathological gambling and substance use disorders: A focus on impulsivity and compulsivity. Psychopharmacology (Berl), 219(2), 469-490. doi:10.1007/s00213-011-2550-7

Lu, Y., Avellaneda, F., Torres, E. D., Rothman, E. F., \& Temple, J. R. (2019). Adolescent cyberbullying and weapon carrying: Cross-sectional and longitudinal associations. Cyberpsychology, Behavior, and Social Networking, 22(3), 173-179. doi:10.1089/cyber.2018.0463

Magoon, M. E., Gupta, R., \& Derevensky, J. (2005). Juvenile Delinquency and adolescent gambling: Implications for the Juvenile justice system. Criminal Justice and Behavior, 32(6), 690-713. doi:10.1177/0093854805279948

Magoon, M. E., \& Ingersoll, G. M. (2006). Parental modeling, attachment, and supervision as moderators of adolescent gambling. Journal of Gambling Studies, 22(1), 1-22. doi:10.1007/s10899-005-9000-6

Mishra, S., Lalumière, M. L., Morgan, M., \& Williams, R. J. (2011). An examination of the relationship between gambling and antisocial behavior. Journal of Gambling Studies, 27(3), 409-426. doi:10.1007/s10899-010-9217-x

Moffitt, T. E., Caspi, A., Harrington, H., \& Milne, B. J. (2002). Males on the life-course-persistent and adolescence-limited antisocial pathways: Follow-up at age 26 years. Development and Psychopathology, 14(1), 179-207. doi:10.1017/S09545 79402001104

Muula, A. S., Rudatsikira, E., \& Siziya, S. (2008). Correlates of weapon carrying among high school students in the United States. Annals of General Psychiatry, 7(1), 8. doi:10.1186/ 1744-859X-7-8

Pickett, W., Craig, W., Harel, Y., Cunningham, J., Simpson, K., Molcho, M., Mazur, J., Dostaler, S., Overpeck, M. D., \& Currie, C. E. (2005). Cross-national study of fighting and weapon carrying as determinants of adolescent injury. Pediatrics, 116(6), e855-e863. doi:10.1542/peds.2005-0607
Pickett, W., Schmid, H., Boyce, W. F., Simpson, K., Scheidt, P. C., Mazur, J., Molcho, M., King, M. A., Godeau, E., Overpeck, M., Aszmann, A., Szabo, M., \& Harel, Y. (2002). Multiple risk behavior and injury: An international analysis of young people. Archives of Pediatrics and Adolescent Medicine, 156(8), 786-793. doi:10.1001/archpedi.156.8.786

Pilver, C. E., Libby, D. J., Hoff, R. A., \& Potenza, M. N. (2013a). Gender differences in the relationship between gambling problems and the incidence of substance-use disorders in a nationally representative population sample. Drug and Alcohol Dependence, 133(1), 204-211. doi:10.1016/j.drugalcdep. 2013.05.002

Pilver, C. E., Libby, D. J., Hoff, R. A., \& Potenza, M. N. (2013b). Problem gambling severity and the incidence of Axis I psychopathology among older adults in the general population. Journal of Psychiatric Research, 47(4), 534-541. doi:10.1016/ j.jpsychires.2012.12.013

Potenza, M. N., Wareham, J. D., Steinberg, M. A., Rugle, L., Cavallo, D. A., Krishnan-Sarin, S., \& Desai, R. A. (2011). Correlates of at-risk/problem Internet gambling in adolescents. Journal of the American Acadademy of Child and Adolescent Psychiatry, 50(2), 150-159.e3. doi:10.1016/j.jaac.2010.11.006

Proimos, J., DuRant, R. H., Pierce, J. D., \& Goodman, E. (1998). Gambling and other risk behaviors among 8th- to 12th-grade students. Pediatrics, 102(2), e23. doi:10.1542/peds.102.2.e23

Rahman, A. S., Pilver, C. E., Desai, R. A., Steinberg, M. A., Rugle, L., Krishnan-Sarin, S., \& Potenza, M. N. (2012). The relationship between age of gambling onset and adolescent problematic gambling severity. Journal of Psychiatric Research, 46(5), 675-683. doi:10.1016/j.jpsychires.2012.02.007

Roberts, A., Landon, J., Sharman, S., Hakes, J., Suomi, A., \& Cowlishaw, S. (2018). Gambling and physical intimate partner violence: Results from the National Epidemiologic Survey on Alcohol and Related Conditions (NESARC). The American Journal on Addictions, 27(1), 7-14. doi:10.1111/ajad.12656

Ruggles, K. V., \& Rajan, S. (2014). Gun possession among American youth: A discovery-based approach to understand gun violence. PLoS One, 9(11), e111893. doi:10.1371/journal. pone. 0111893

Schepis, T. S., Desai, R. A., Smith, A. E., Cavallo, D. A., Liss, T. B., McFetridge, A., Potenza, M. N., \& Krishnan-Sarin, S. (2008). Impulsive sensation seeking, parental history of alcohol problems, and current alcohol and tobacco use in adolescents. Journal of Addiction Medicine, 2(4), 185-193. doi:10.1097/ADM.0b013e31818d8916

Shaffer, H. J., Labrie, R., Scanlan, K. M., \& Cummings, T. N. (1994). Pathological gambling among adolescents: Massachusetts Gambling Screen (MAGS). Journal of Gambling Studies, 10(4), 339-362. doi:10.1007/BF02104901

Slavin, M., Pilver, C. E., Hoff, R. A., Krishnan-Sarin, S., Steinberg, M. A., Rugle, L., \& Potenza, M. N. (2013). Serious physical fighting and gambling-related attitudes and behaviors in adolescents. Journal of Behavioral Addictions, 2(3), 167-178. doi:10.1556/JBA.2.2013.009

Slutske, W. S., Eisen, S., Xian, H., True, W. R., Lyons, M. J., Goldberg, J., \& Tsuang, M. (2001). A twin study of the association between pathological gambling and antisocial personality disorder. Journal of Abnormal Psychology, 110(2), 297-308. doi:10.1037/0021-843X.110.2.297

Thurnherr, J., Michaud, P.-A., Berchtold, A., Akré, C., \& Suris, J.-C. (2009). Youths carrying a weapon or using a weapon in a 
fight: What makes the difference? Health Education Research, 24(2), 270-279. doi:10.1093/her/cyn017

Turner, N. E., Preston, D. L., Saunders, C., McAvoy, S., \& Jain, U. (2009). The relationship of problem gambling to criminal behavior in a sample of Canadian male federal offenders. Journal of Gambling Studies, 25(2), 153-169. doi:10.1007/ s10899-009-9124-1

van Geel, M., Vedder, P., \& Tanilon, J. (2014). Bullying and weapon carrying: A meta-analysis. JAMA Pediatrics, 168(8), 714-720. doi:10.1001/jamapediatrics.2014.213

Vitaro, F., Brendgen, M., Ladouceur, R., \& Tremblay, R. E. (2001). Gambling, delinquency, and drug use during adolescence: Mutual influences and common risk factors. Journal of Gambling Studies, 17(3), 171-190. doi:10.1023/ A:1012201221601

Volberg, R. A., Gupta, R., Griffiths, M. D., Olason, D. T., \& Delfabbro, P. (2010). An international perspective on youth gambling prevalence studies. Internatonal Journal of Adolescent Medicine and Health, 22(1), 3-38. doi:10.1515/ IJAMH.2010.22.1.3
Weinstock, J. (2018). Call to action for gambling disorder in the United States. Addiction, 113(6), 1156-1158. doi:10.1111/ add. 14225

Weinstock, J., Whelan, J. P., \& Meyers, A. W. (2004). Behavioral assessment of gambling: An application of the timeline followback method. Psychological Assessment, 16(1), 72-80. doi:10.1037/1040-3590.16.1.72

Yip, S. W., Desai, R. A., Steinberg, M. A., Rugle, L., Cavallo, D. A., Krishnan-Sarin, S., \& Potenza, M. N. (2011). Health/ functioning characteristics, gambling behaviors, and gamblingrelated motivations in adolescents stratified by gambling problem severity: Findings from a high school survey. The American Journal on Addictions, 20(6), 495-508. doi:10.1111/ j.1521-0391.2011.00180.x

Zhai, Z. W., Yip, S. W., Steinberg, M. A., Wampler, J., Hoff, R. A., Krishnan-Sarin, S., \& Potenza, M. N. (2017). Relationships between perceived family gambling and peer gambling and adolescent problem gambling and binge-drinking. Journal of Gambling Studies, 33(4), 1169-1185. doi:10.1007/s10899017-9670-x 